\title{
teatro nacional
}

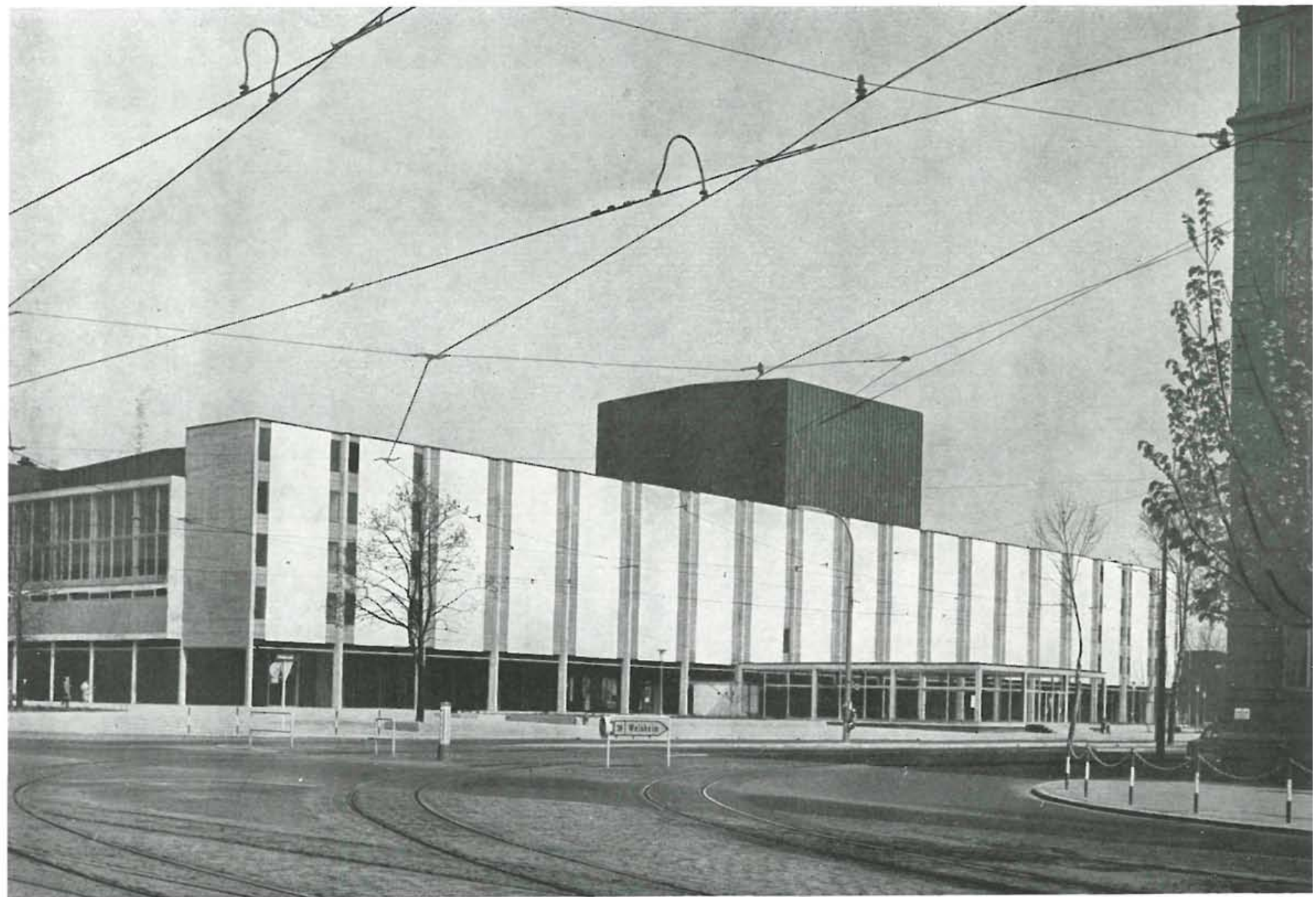

\section{Mannheim}

Situado en la plaza Goethe, el Teatro Nacional forma parte de los edificios de Mannheim, que son un testimonio importante de la restauración de la ciudad y del entusiasmo de sus ciudadanos por el teatro.

El proyecto sufrió varias modificaciones durante su desarrollo. Se intentaba conseguir una diferenciación de las dos salas existentes en el mismo edificio. Una decisión muy importante del Consejo de Administración permitió instalar las salas de ensayos debajo de los escenarios. Con esta restricción de espacio fué posible limitar, desde el punto de vista urbanístico, el volumen total del edificio en la plaza Goethe con dimensiones moderadas.

Consideraciones económicas y de organización condujeron a situar los escenarios de las salas al mismo nivel y con el mismo eje. El edificio, por ser de planta trapezoidal, permite la creación de dos salas de distinta capacidad: éste tiene una longitud de $133 \mathrm{~m}$ y una anchura de $54,70 \mathrm{~m}$ y $41,10 \mathrm{~m}$, respectivamente, correspondientes a los fondos de las distintas salas. La cubierta se halla a un nivel de $18 \mathrm{~m}$ de la rasante de la calle. La diferencia de nivel entre la torre del escenario y la sala más grande es de 33,5 metros.

Mientras las fachadas longitudinales están cerradas con los huecos indispensables para entrada y ventilación, las laterales son totalmente acristaladas. De esta forma, los vestíbulos de ambas salas amplían su visión óptica hacia los parques Luisenpark y Friedrichsring.

Otro punto muy importante que ha mandado en este proyecto ha sido el de buscar la protección oportuna de los refugios subterráneos, aún existentes de la segunda guerra mundial, que ocupan bastante superficie y cuyo techo se encuentra a $80 \mathrm{~cm}$ sobre el nivel del terreno. A causa de esta necesidad de respetar dichos refugios, se han elevado los niveles de los escenarios a la segunda planta, situada a $4,70 \mathrm{~m}$ sobre el nivel de la plaza.

En el amplio hall, común para las dos salas, se distribuyen las taquillas, guardarropas, bar y los accesos. 


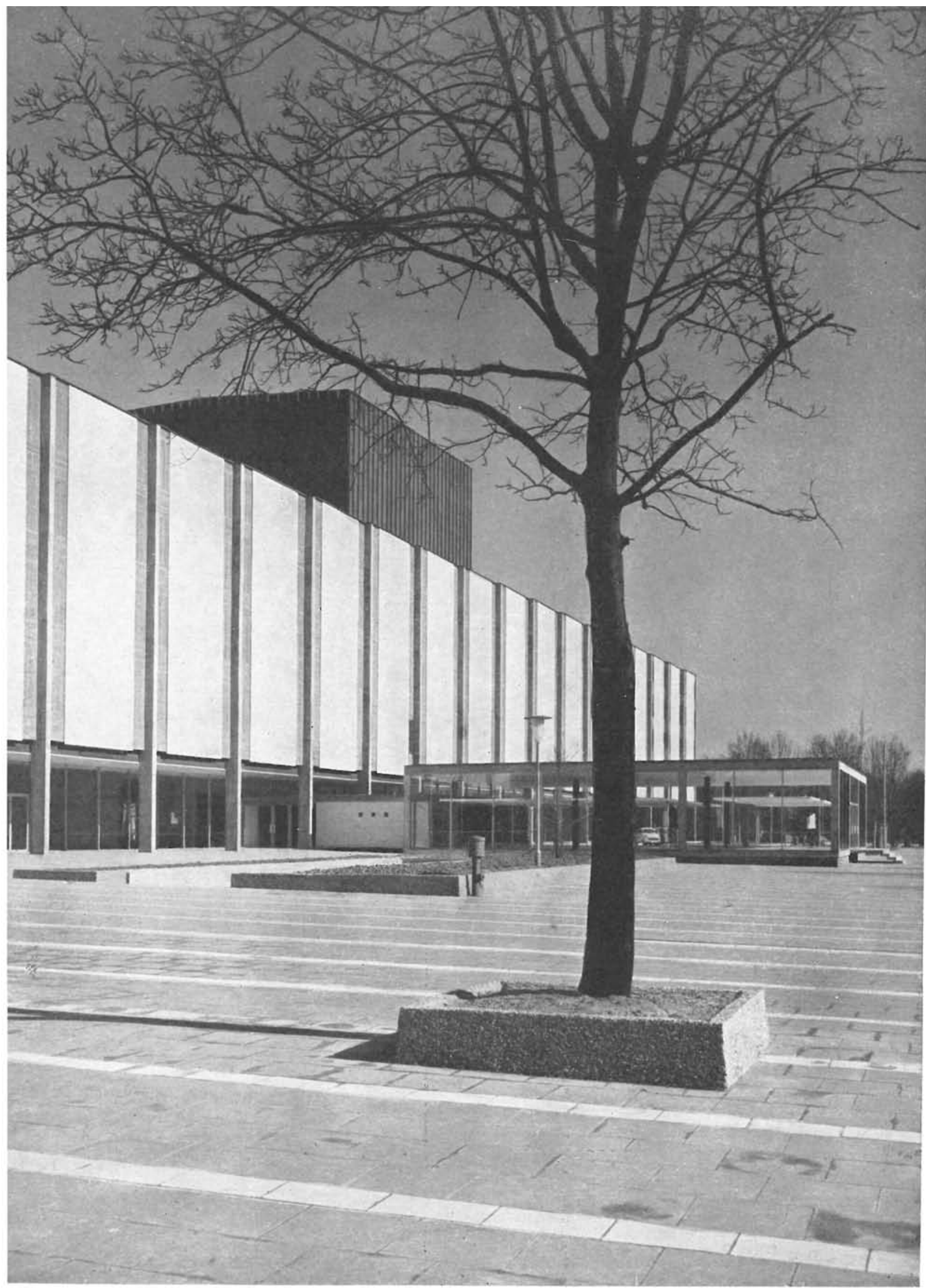

Fachada principal. 


\section{perspectiva axonométrica}

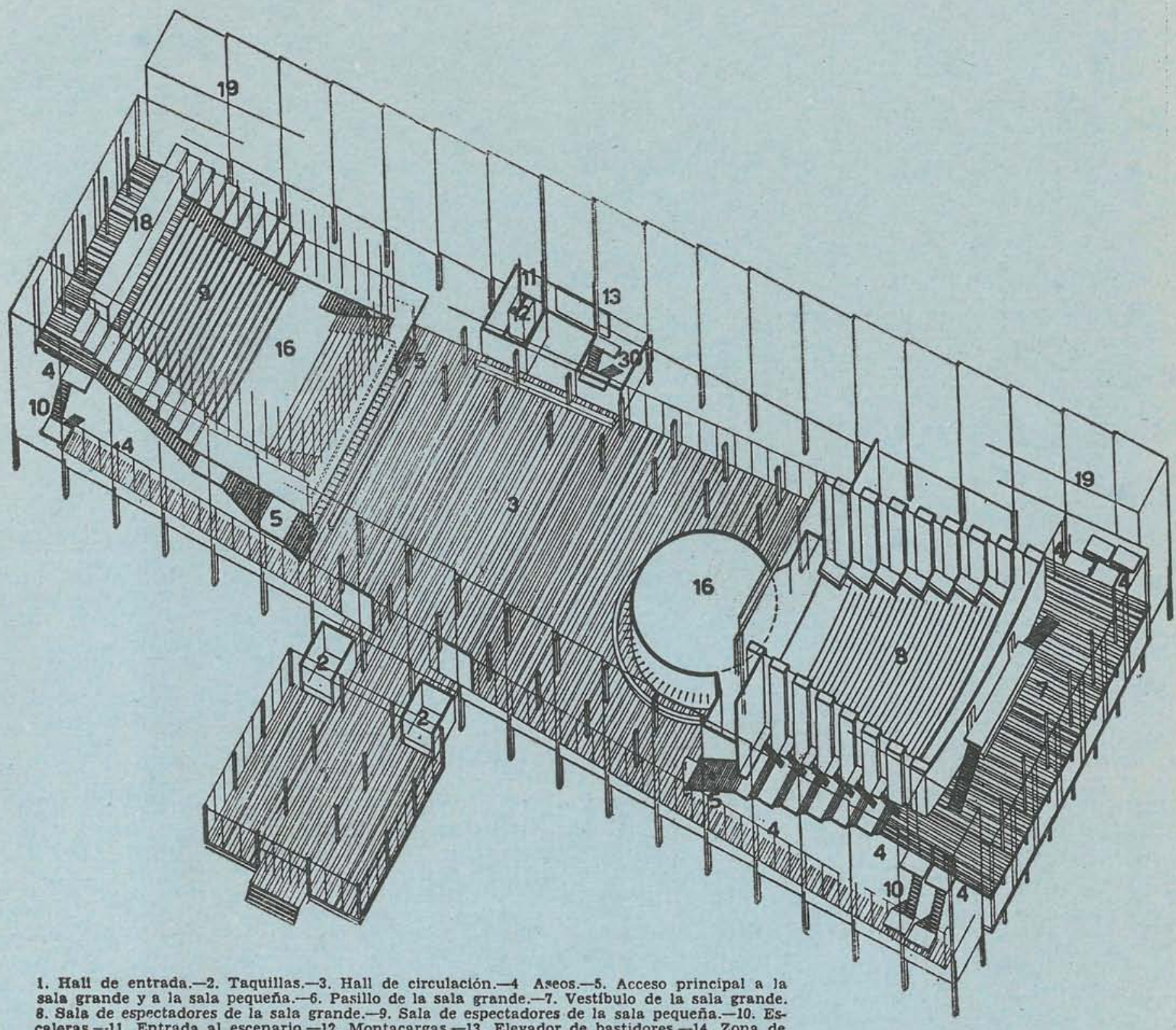

sala grande y a la sala pequena.-6. Pasillo de la sala grande.-7. Vestíbulo de la sala grande. 8. Sala de espectadores de la sala grande. -9 . Sala de espectadores de la sala pequeña. -10 . Escaleras.-11. Entrada al escenario.-12. Montacargas.-13. Elevador de bastidores, -14 . Zona de rransporte. -15 . Escenarios auxiliares.-16. Escenarios.-17. Almacenes. -18. Cabina de direcclo $y$ de sonido. -19 . Camerinos. -20 . Cantina con cocina, -21 . Sala de balle de butacas de la sala pequeñ.-23. Escena inferior de la sala pequena.- 2 . E instrumentos. 37. Cuarto de afinamiento.-28. Escenario de ensayo.-29. Ensayo de la orquesta.-30. Escaleras de servicio.

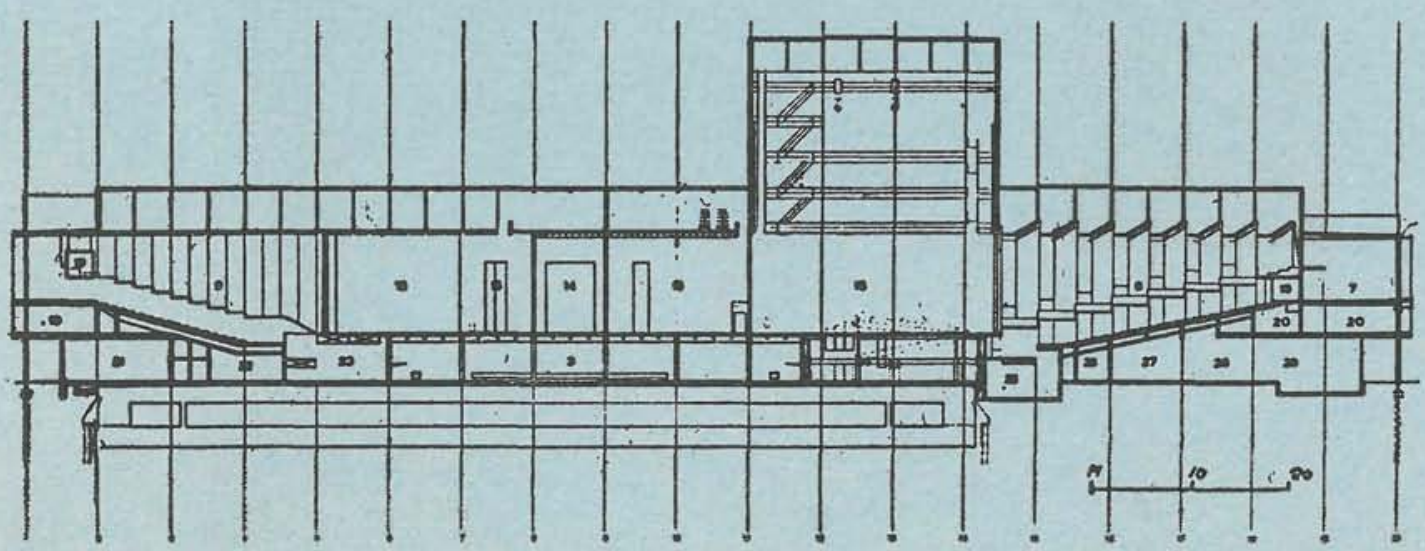

s e c c i ó n 

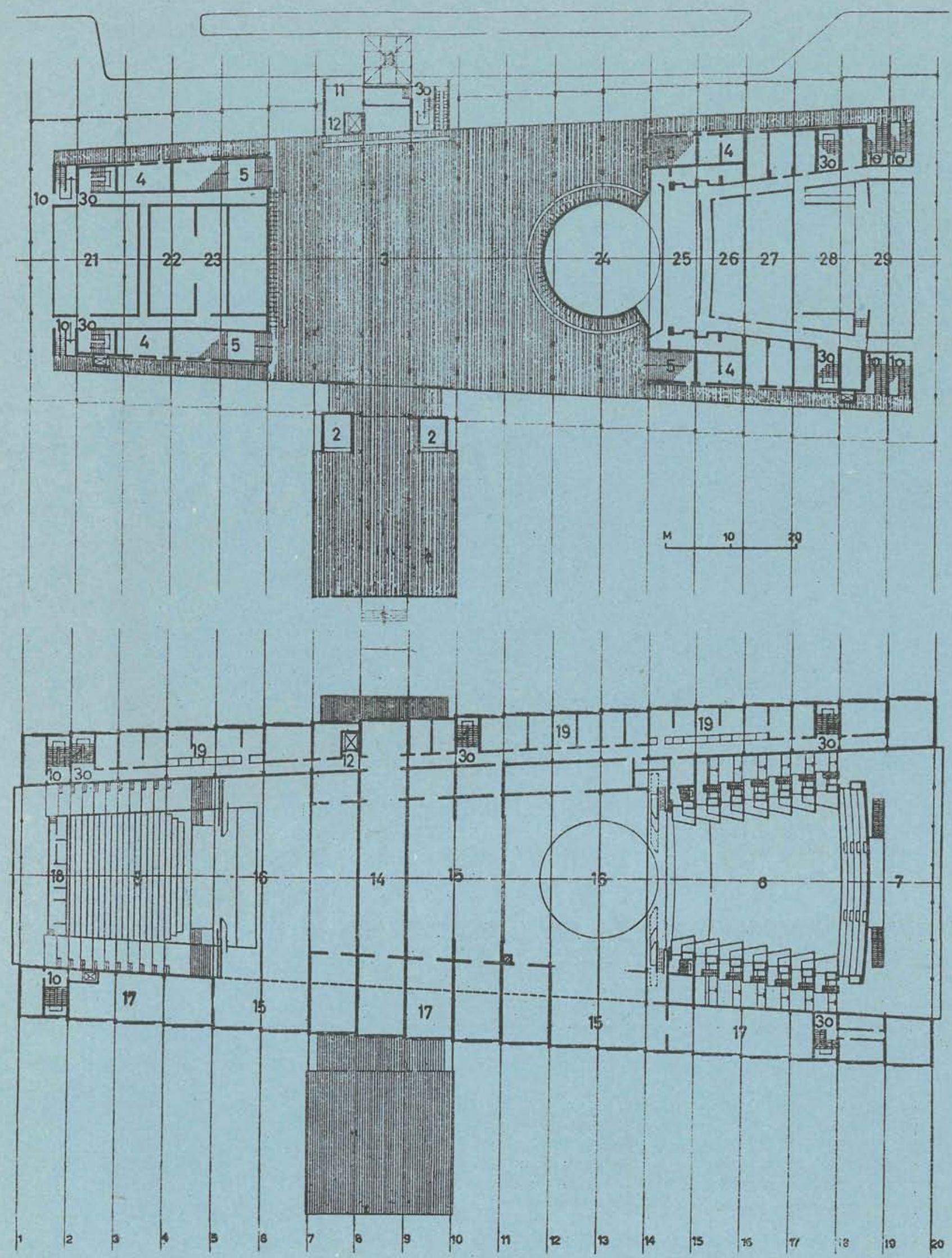

(Ver leyenda en página anterior.)

plantas 

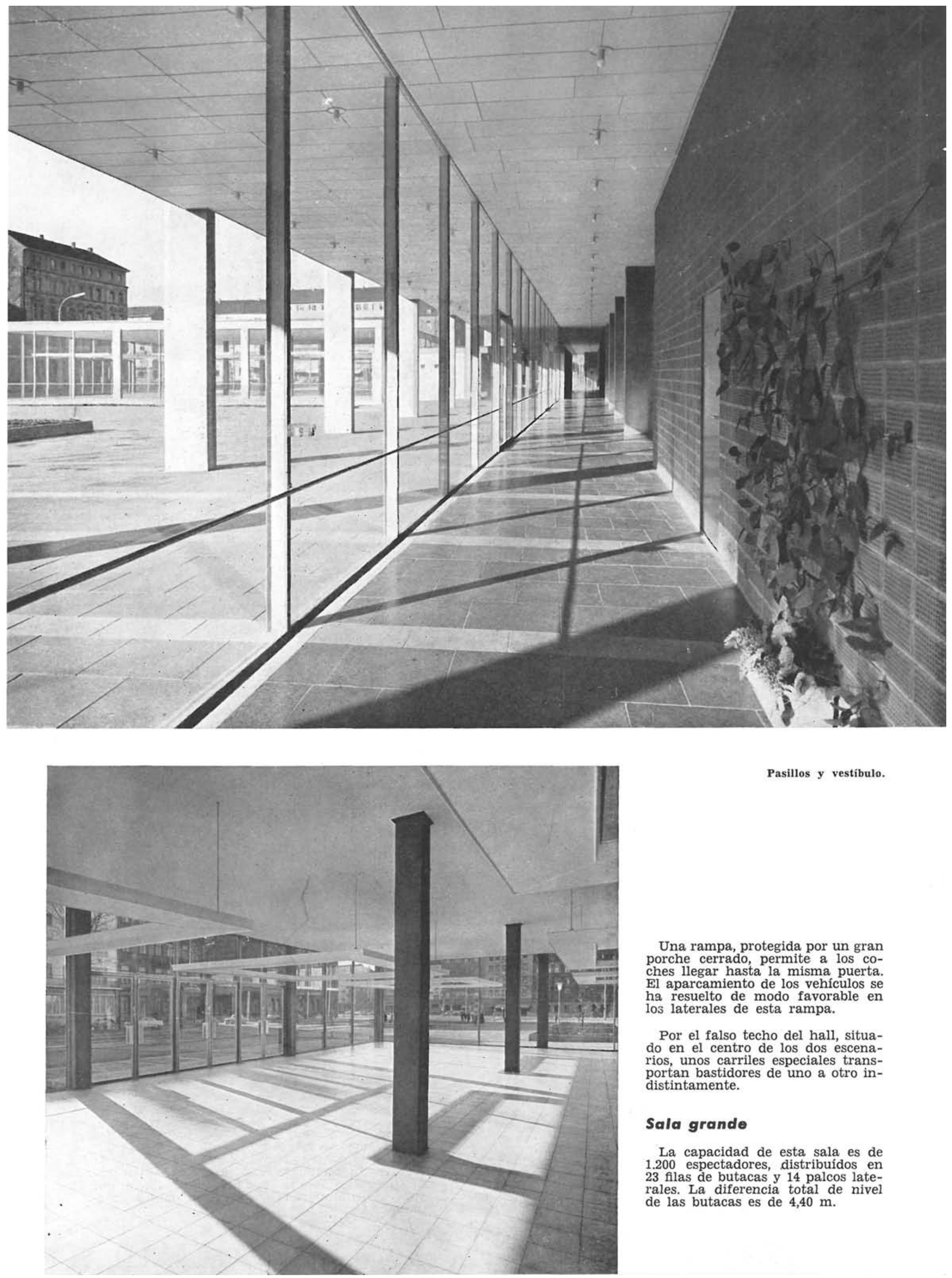

Pasillos y vestibulo, 

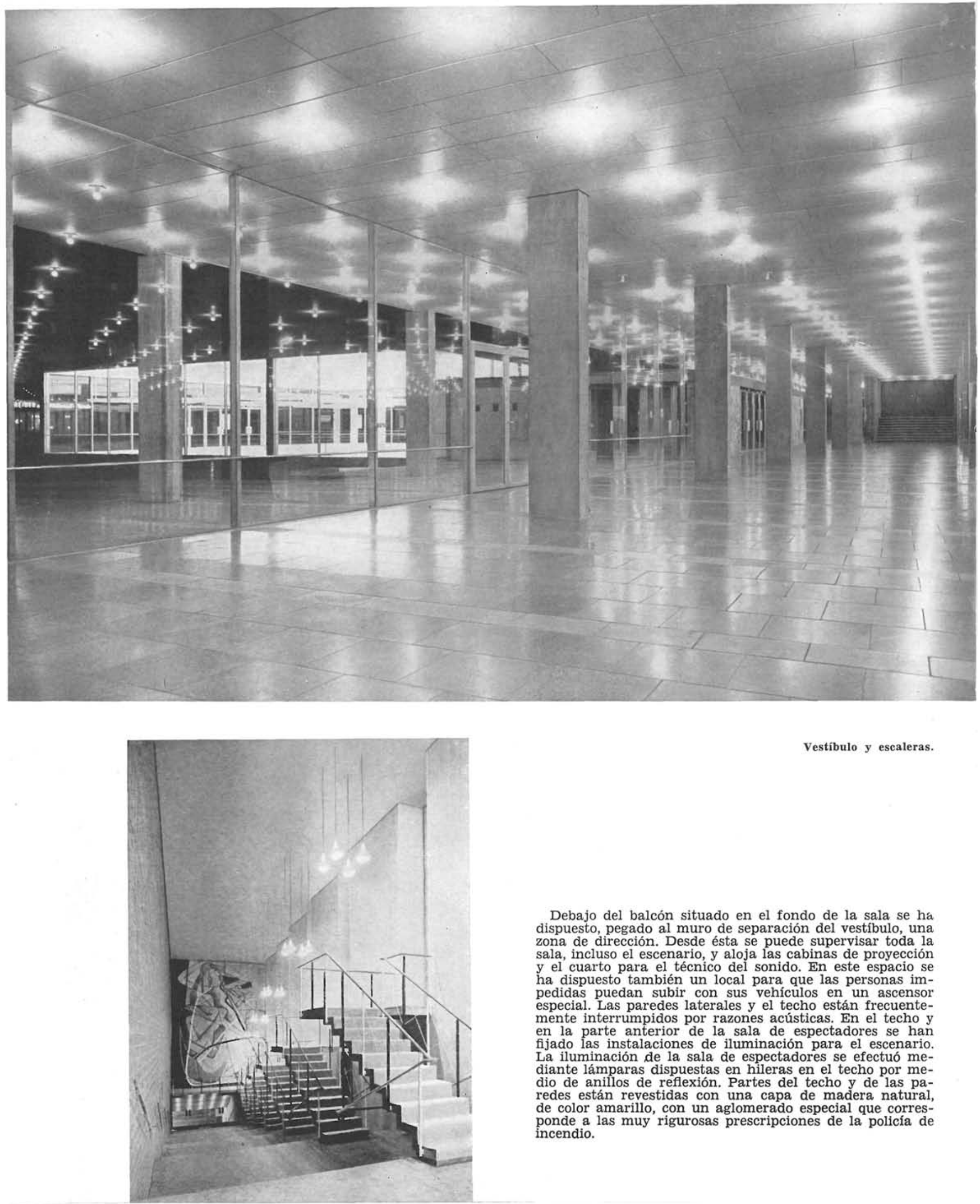

Vestíbulo y escaleras.

Debajo del balcón situado en el fondo de la sala se há dispuesto, pegado al muro de separación del vestíbulo, una zona de dirección. Desde ésta se puede supervisar toda la sala, incluso el escenario, y aloja las cabinas de proyección y el cuarto para el técnico del sonido. En este espacio se ha dispuesto también un local para que las personas impedidas puedan subir con sus vehículos en un ascensor especial. Las paredes laterales y el techo están frecuentemente interrumpidos por razones acústicas. En el techo y mente interrumpidos por razones acústicas. En el techo y en la parte anterior de la sala de espectadores se han
fijado las instalaciones de iluminación para el escenario. La iluminación de la sala de espectadores se efectuó mediante lámparas dispuestas en hileras en el techo por medio de anillos de reflexión. Partes del techo y de las paredes están revestidas con una capa de madera natural, de color amarillo, con un aglomerado especial que corresponde a las muy rigurosas prescripciones de la policía de incendio. 


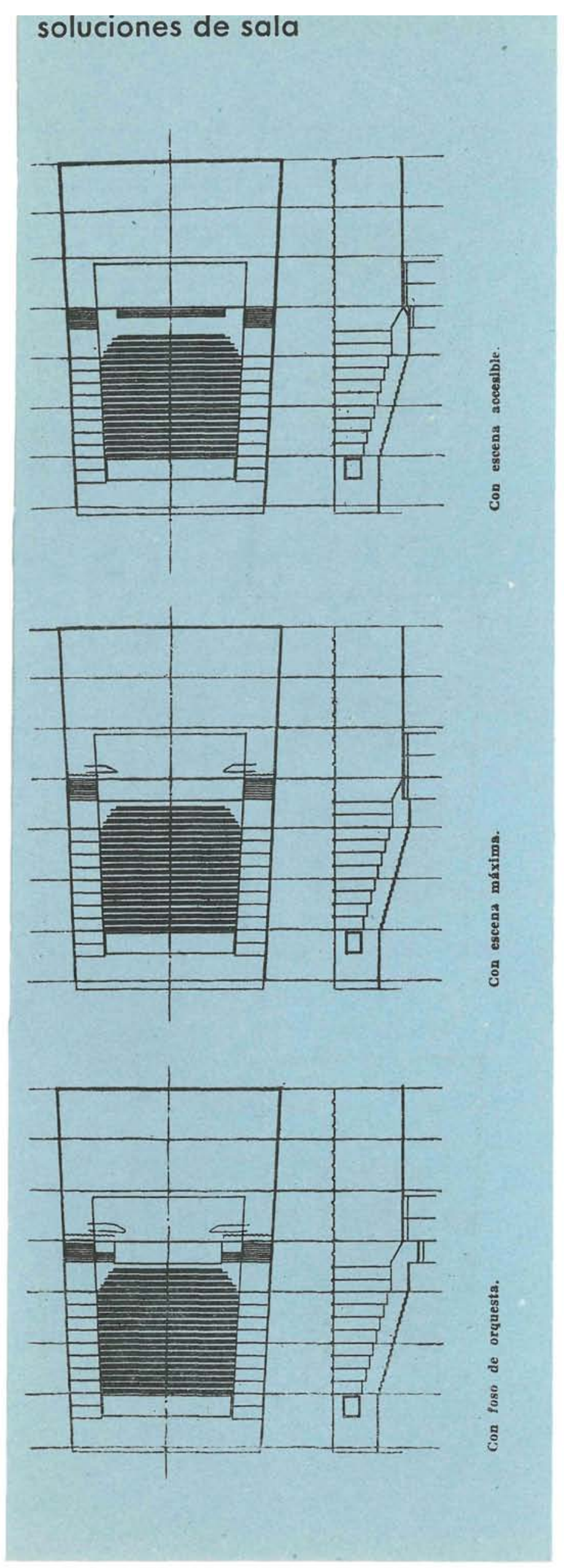


soluciones de sala
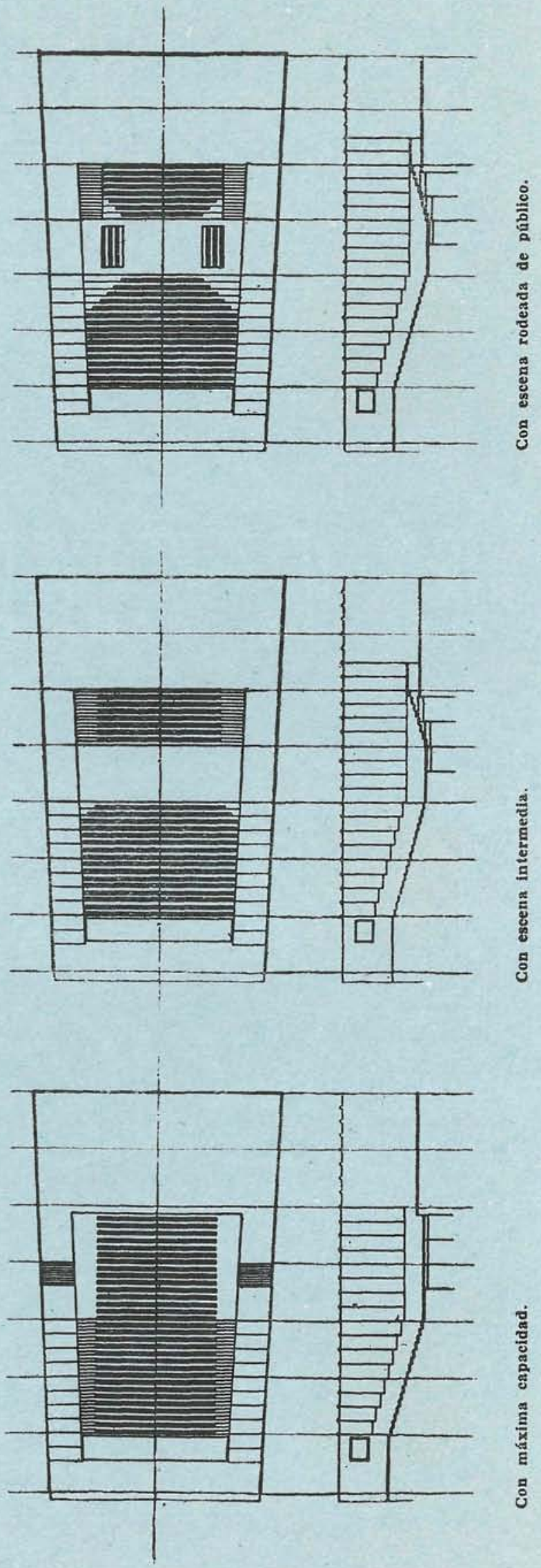


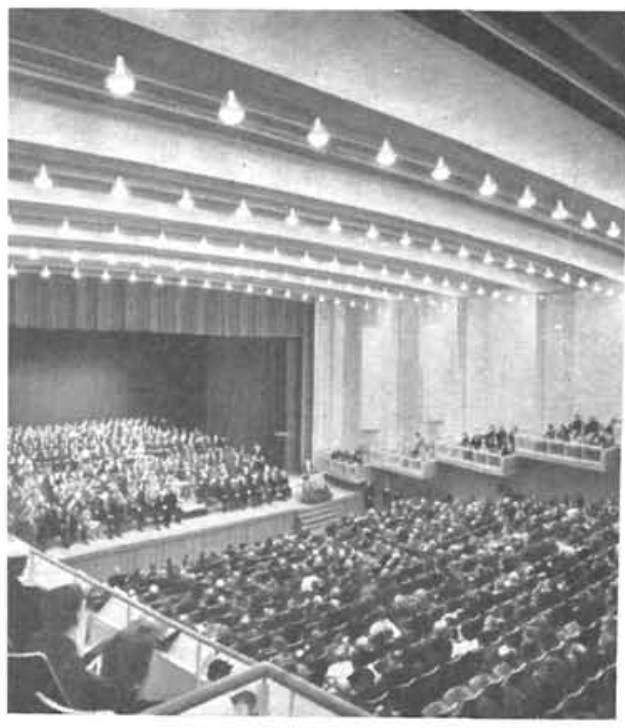

i) escenario tiene unas dimensiones de 26 tros por $23 \mathrm{~m}$. También dispone de un es1ario giratorio montado con un diámetro $17 \mathrm{~m}$. En el conjunto del escenario existen aiveles distintos $y$, por tanto, éste puede jptar tres posiciones. El juego de posibililes para lograr efectos escénicos distintos de 20 soluciones.

as butacas se han realizado teniendo en inta el deseo de amplitud. El acceso, tanto as butacas como a los palcos, se realiza por laterales, valiéndose de dos amplias escaas de suave pendiente.

\section{la pequeña}

Iquí se ha tratado de conseguir la mayor zibilidad haciendo una unidad de la sala il escenario. Los accesos e iluminación se a resuelto con el mismo criterio que en la a grande. Esta sala pequeña puede utilise, aparte de su uso normal, como sala conferencias, sala de conciertos, escenario boxeo.... ya que la parte posterior del esเario, mediante dispositivos especiales, perte la adaptación de un pequeño graderío n la ayuda de procedimientos electrónicos, * permiten la creación de niveles, se amplía aforo de la sala de 600 hasta- 800 espectaes cuando lo exigen las circunstancias.

a norma fundamental que ha regido este yecto ha sido el lograr un perfecto funcioniento. El decorado de todo el edificio se ctuó con sobriedad, elegancia y sencillez.
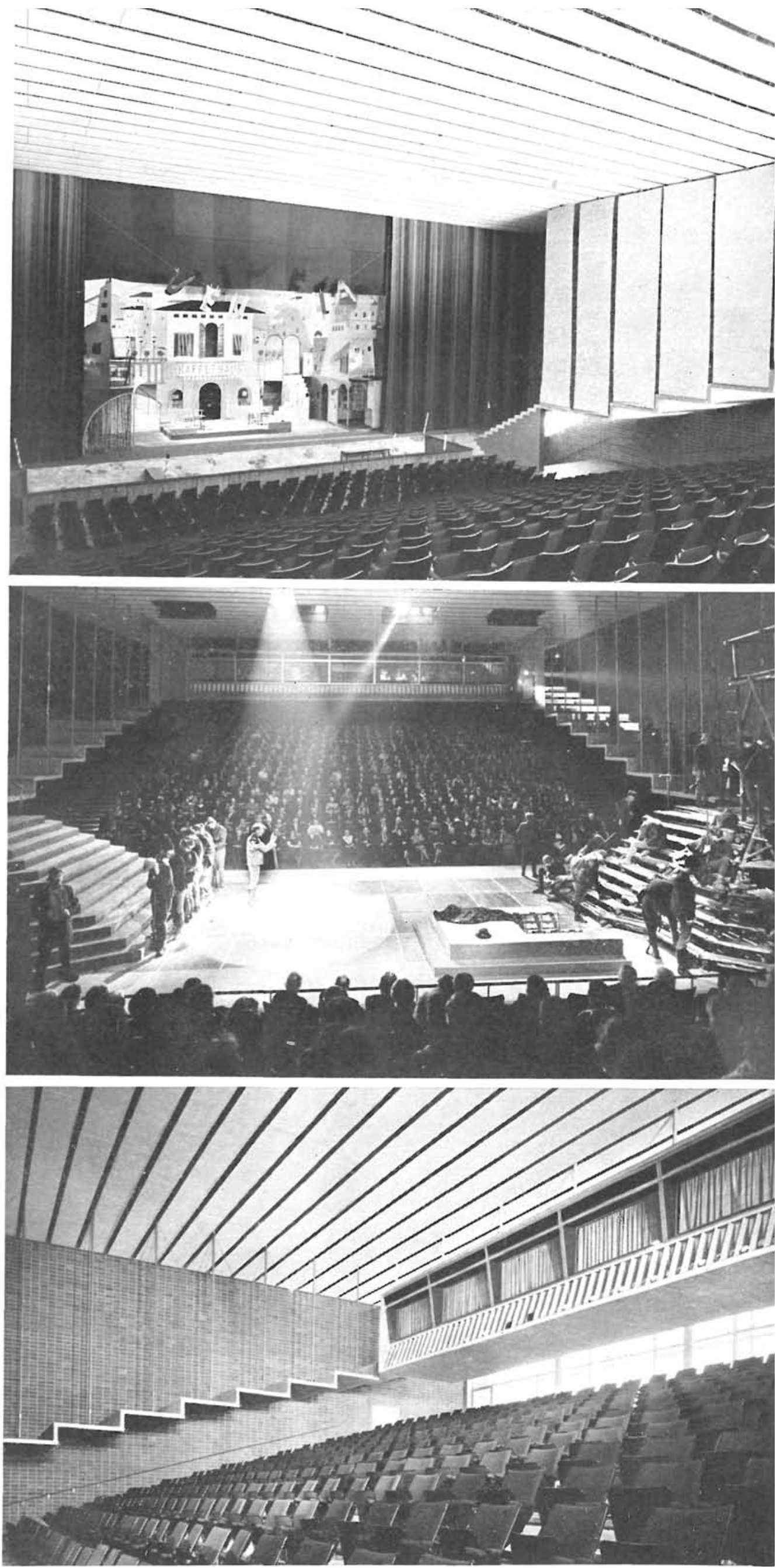


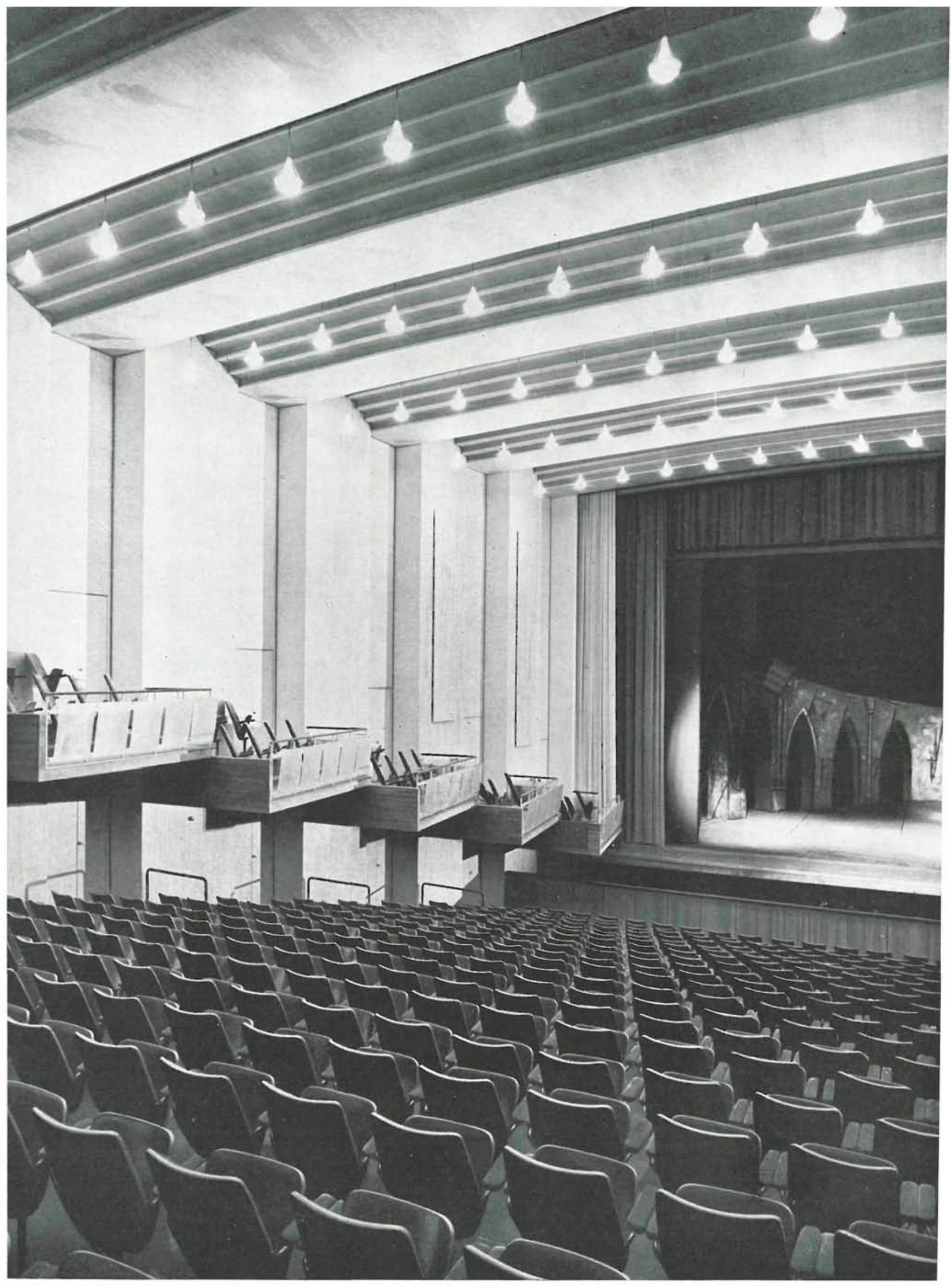

